\title{
SISTEM INFORMASI PENGELOLAAN BANK SAMPAH SAMPURNA BERKAH BERBASIS WEBSITE
}

\author{
Suleman, Nuzul Imam Fadlilah² ${ }^{2}$ Angga Ardiansyah³ ${ }^{3}$ Sandra Jamu Kuryanti $^{4}$ \\ 1,2,4 Universitas Bina Sarana Informatika \\ ${ }^{3}$ Universitas Nusa Mandiri \\ Email: ${ }^{1}$ suleman.sln@bsi.ac.id, 2nuzul.nfh@bsi.ac.id, ${ }^{3}$ angga.axr@nusamandiri.ac.id, \\ 4sandra.sjk@bsi.ac.id
}

\begin{abstract}
Abstrak
Sampah merupakan salah satu permasalahan yang cukup serius untuk berbagai wilayah di Indonesia, baik perkotaan maupun di perdesa, salah satunya yaitu sampah atau limbah rumah tangga, salah satu cara untuk mengurangi permasalahan tersebut yaitu dengan melibatkan masyarakat unutk menyelesaikan permasalahan tersebut melalui bank sampah. Bank sampah sampurna berkah yang berada di desa sidapurna merupakan salah satu bank sampah yang ada di kabupaten tegal. Dalam proses pengolahan dan penyimpanan data nasabah bank sampurna berkah masih menggunakan cara manual yaitu dengan mencatat setiap transakasi kedalam buku, sehingga sering kali timbul permasalahan seperti data rusak atau hilang, duplikasi data, serta buku laopran yang semakin lama semakin banyak dan menumpuk. Sehingga membutuhkan cara untuk memecahkan permasalahan tersebut yaitu dengan dibangunnya sistem infromasi yang bebasis website agar memudahkan petugas bank sampah dalam mencatat setiap transaksi serta pencatatan data yang lebih cepat dan akurat. Pembuatan Sistem informasi bank sampah ini mengguakan framework codeigniter dan menggunakan metode waterfall.
\end{abstract}

Kata Kunci: Sistem informasi bank sampah; codeigniter; website

\begin{abstract}
Garbage is a serious problem for various regions in Indonesia, both urban and rural areas, one of which is garbage or household waste, one way to reduce this problem is by involving the community to solve these problems through waste banks. The Sampurna Blessing Waste Bank located in Sidapurna Village is one of the garbage banks in Tegal Regency. In the process of processing and storing customer data, Sampurna Blessing Bank still uses the manual method, namely by recording every transaction into a book, so that often problems arise such as damaged or lost data, data duplication, and book reports which are getting more and more accumulated So it requires a way to solve this problem, namely by building a website-based information system to make it easier for waste bank officers to record every transaction and record data more quickly and accurately. Making this waste bank information system uses a codeigniter framework and uses the waterfall method.
\end{abstract}

Keywords: Waste bank information system; codeigniter; website

\section{PENDAHULUAN}

Sampah limbah rumah tangga, umumnya terdiri dari sampah organik dan anorganik yang dihasilkan dari aktivitas rumah tangga. Misalnya, buangan dari dapur, taman, debu, dan alat-alat rumah tangga. Sebagian besar sampah terdiri atas bahan organik, kertas, logam, kaca, dan plastik. Sampah yang berasal dari industri, berbeda komposisinya dengan sampah yang berasal dari perumahan (rumah tangga). Sampah rumah tangga mempunyai jumlah zat organik yang jauh lebih banyak. Sampah organik umumnya terdiri atas sisa-sisa sayuran, buah-buahan, dan biji-bijian. Sampah kaleng dan plastik tidak dapat terurai secara biologis. Plastik mengandung PVC (polyvinilchlorida) dan pthalate yang jika terbakar menyebabkan polusi udara dan berpotensi menimbulkan kanker (Suryati, 2009). Oleh karena itu untuk mengurangi limbah sampah yang ada pada kabupaten Tegal salah satu upanya yang dilakukan adalah dengan membangun 

2012 tentang pedoman pelaksanaan reduce, reuse, dan recycle melalui bank sampah Pasal 1 menyatakan Bank sampah adalah tempat pemilahan dan pengumpulan sampah yang dapat didaur ulang dan/atau diguna ulang yang memiliki nilai ekonomi (Riyanto \& Kusumastuti, 2015).

Dikabupaten Tegal sudah ada beberapa bank sampah yang aktif, yang berada dibawah naungan ASOSBI (Asosiasi Bank Sampah Indonesia) kabupaten tegal. Dalam proses pengelolaan bank sampah untuk porses utamanya mirip dengan bank konvensional pada umumnya yaitu menabung dan menarik uang.perbedaannya dengan bank konvenisonal, bank sampah ini yang ditabung bukanlah uang akan tetapi sampah yang sudah dikumpulkan oleh nasabah kemudian disetorkan ke bank sampah, sampah-sampah tersebut nantinya akan di sortir sesuai dengan jenis sampahnya dan diberikan harga sesuai harga yang berlaku saat itu.

Salah satu bank sampah yang ada di kabupaten tegal adalah Bank Sampah Sampurna Berkah merupakan bank sampah yang berada di desa Sidapurna, Kec. Dukuhturi yang sudah mempunyai cukup banyak nasabah yaitu 150 nasabah, pada bank sampah sampurna berkah ini dalam proses pengelolaan data nasabah masih menggunakan cara manual yaitu dengan mencatat pada buku serta belum memanfaatkan teknologi informasi.

Dengan banyaknya data yang diolah oleh bank sampah sampurna berkah yaitu berkaitan dengan data nasabah, data transaksi, data tabungan serta harga terbaru dari sampah-sampah yang nantinya akan di taung oleh nasabah. jika dilakukan pengelolaan secara manual, akan menimbulkan beberapa permasalahan seperti rusaknya media penyimpanan data, data akan mudah hilang, untuk mencari data lama akan membutuhkan waktu yang cukup lama pula sehingga kurang afesien.

Dari permasalahan-permasalahan yang ada maka peneliti akan membangun sistem informasi bank sampah berbasis website. dengan adanya sistem ini nantinya akan membantu pengelola bank sampah sampurna berkah dalam proses pengelolaan data agar lebih mudah serta tidak memakan banyak waktu.

\section{METODE PENELITIAN}

\subsection{Sistem Informasi}

Sistem informasi adalah suatu sistem di dalam suatu organisasi yang mempertemukan kebutuhan pengolahan transaksi harian yang mendukung fungsi operasi organisasi yang bersifat manajerial dengan kegiatan strategi dari suatu organisasi untuk dapat menyediakan laporan-laporan yang diperlukan oleh pihak luar tertentu.(Sutabri, 2012)

\subsection{Website}

Menurut Abdulloh dalam (Sutikno, 2019) website atau disingkat web adalah sekumpulan halaman yang terdiri atas beberapa laman yang berisi informasi dalam bentuk data digital, baik berupa teks, gambar, video audio, dan animasi lainnya yang disediakan melalui jalur koneksi internet.

\subsection{PHP (Personal Hypertext Prepocessor)}

Menurut Hidayati dalam (Maryani et al., 2018) PHP merupakan bahasa yang hanya dapat berjalan pada serveryang hasilnya dapat ditampilkan pada client.

\subsection{Basis Data}

Menurut Rosa dan Salahhudin dalam (Imaniawan \& Elsa, 2017)"Sistem basis data adalah sistem terkomputerisasi yang tujuan utamanya adalah memelihara data yang sudah diolah atau informasi dan membuat informasi tersedia saat dibutuhkan". Pada intinya basis data adalah media untuk menyimpan data agar dapat diakses dengan mudah dan cepat.

\subsection{Metode Waterfall}

Menurut Pressman Metode air terjun atau yang sering disebut metode waterfall sering dinamakan siklus hidup klasik (classic life cycle), dimana hal ini menggambarkan pendekatan yang sistematis dan juga berurutan pada pengembangan perangkat lunak. dimulai dengan spesifikasi kebutuhan pengguna lalu berlanjut melalui tahapan-tahapan perencanaan (planning). pemodelan (modeling), konstruksi (construction). serta penyerahan sistem ke para pelanggan/pengguna (deployment), yang diakhiri dengan dukungan pada perangkat lunak lengkap yang dihasilkan (Sanubari et al., 2020) 


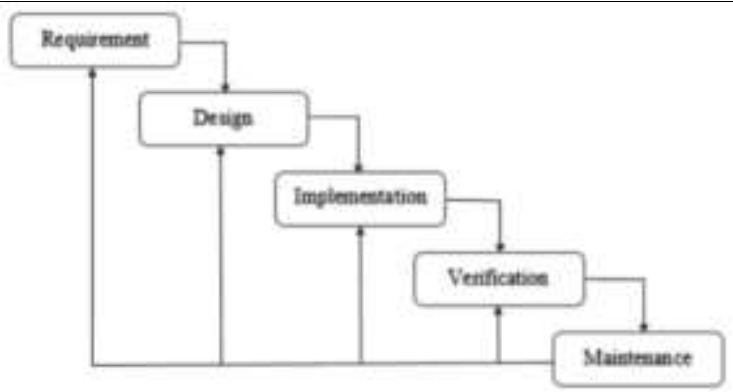

Sumber : (Sanubari et al., 2020)

Gambar 1. Tahapan Metode waterfall

Pada gambar 1 menjelaskan tentang tahapan yang ada pada metode waterfall yaitu Requirement, Design, Implementation, Verification dan Maintenance.

\subsection{Codeigniter}

Codelgniter adalah sebuah framework bahasa pemrograman PHP. Codelgniter bisa dibilang framework PHP paling populer di Indonesia berkat kemudahan yang ditawarkan dalama penggunaannya. Maka tak heran jika situs2 besar seperti kompas.com dan okezone.com juga mengadopsi sistem ini sebagai core engine websitenya. Codelgniter menawarkan kemudahan serta standarisasi dalam proses pengembangan website dan aplikasi berbasis web. Dengan Codelgniter proses pengembangan website menjadi lebih cepat dan terstandar. Standar ini sangat berguna dalam pengembangan website yang dikerjakan oleh tim. (Komputer, 2014)

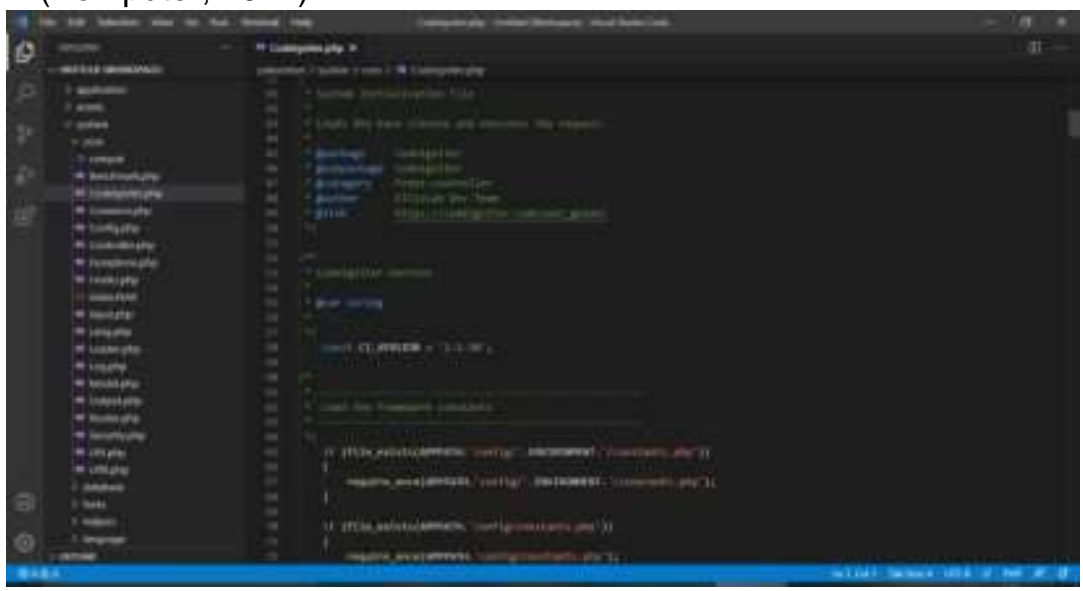

Sumber : Penulis

Gambar 2. Tampilan Codelgniter

Pada Gambar 2 merupakan tampilan dari versi Codeigniter yang digunakan dalam proses pembangunan system

\section{HASIL DAN PEMBAHASAN}

Hasil dari penelitian ini adalah sebuah system informasi yang dapat digunakan untuk pengolahan data transaksi yang ada pada bank sampah sampurna berkah, dari proses pendaftaran nasabah hingga.

\subsection{Entity Relationship Diagram (ERD)}

Pemodelan Basis data yang digunakan pada system informasi bank sampah sampurna berkah yaitu Entity Relationship Diagram (ERD). Menurut Mohammed dkk Entity Relationship Diagram atau ERD adalah sebuah diagram struktural yang digunakan untuk merancang sebuah database. Sebuah ERD mendeskripsikan data yang akan disimpan dalam sebuah sistem maupun batasannya. Komponen utama yang terdapat di dalam sebuah ERD adalah entity set, relationship set, dan juga constraints (Latukolan et al., 2019). 
Pada system ini ERD menggambarkan hubungan antar entitas pada bank sampah sampurna berkah.

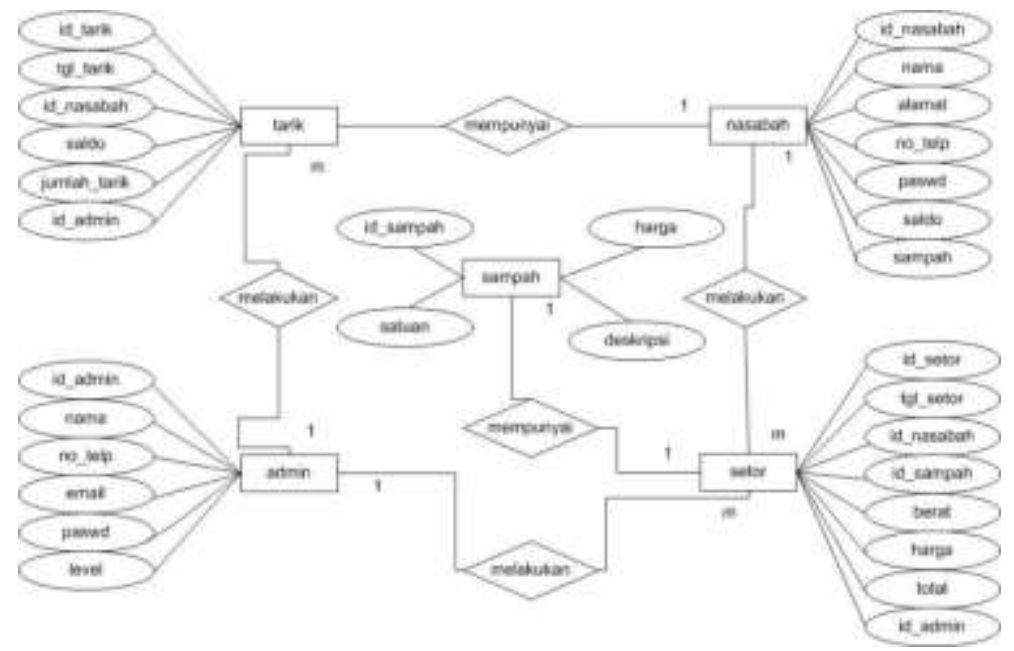

Gambar 3. Entity Relationship Diagram (ERD) system informasi bank sampah sampurna berkah

Sumber: Penulis

\subsection{Logical Record Structure (LRS)}

Menurut Andriansyah dalam (Irnawati \& Listianto, 2018) LRS adalah transformasi dari penggambaran ERD dalam bentuk yang paling jelas dan mudah untuk dipahami.

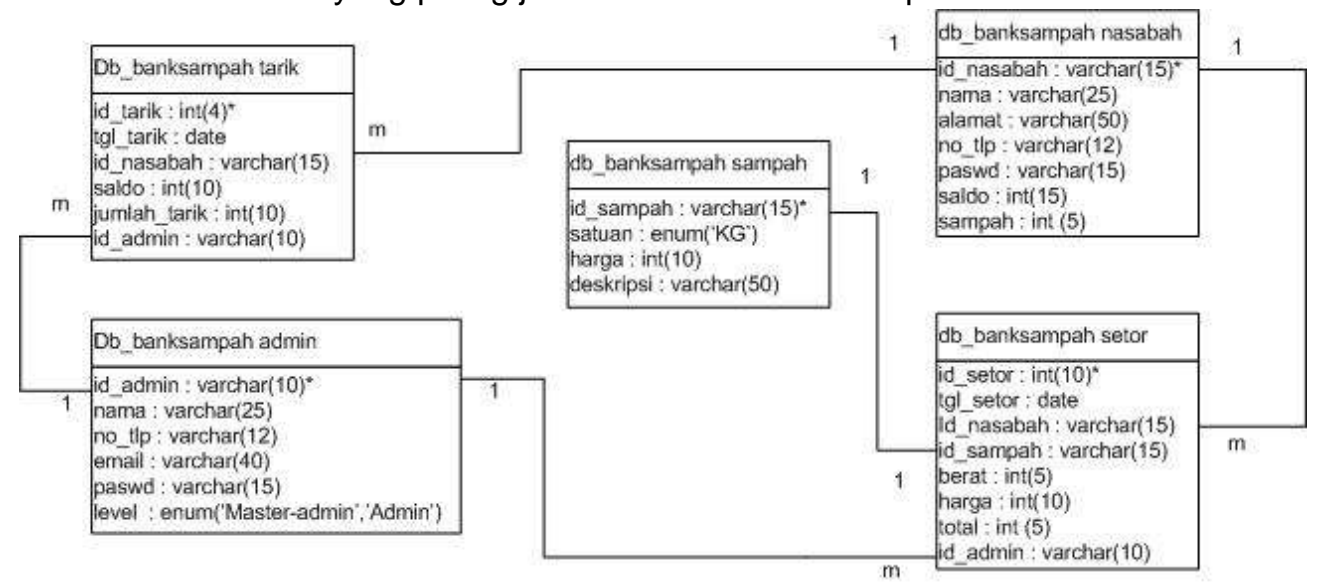

Gambar 4. Logical Record Structure (LRS) system informasi bank sampah sampurna berkah Sumber : Penulis

\subsection{Implementasi}

Pada tahap ini dilakukan proses pembangunan system informasi bank sampah sampurna berkah dengan menggunakan framework codeigniter. Berikut adalah tampilan antarmuka dari system bank sampah sampurna berkah.

a. Tampilan halaman login

Pada halaman login dapat digunakan oleh admin dan nasabah agar bisa mengakses system informasi bank sampak sampurna berkah. 


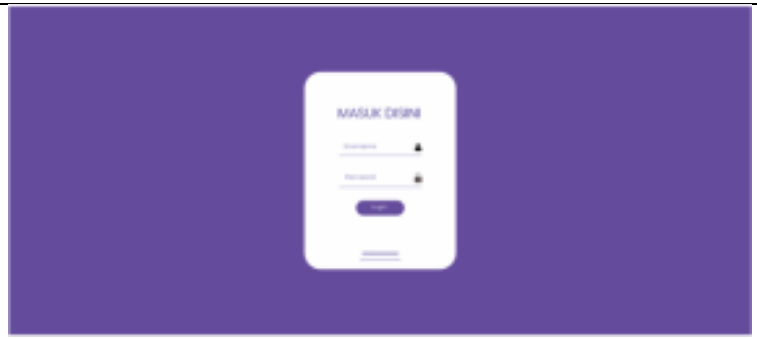

Gambar 5. Halaman login

b. Tampilan Dasboard Admin

Pada tampilan utama dasboard admin akan menampilkan data admin yang mengelola sistem informasi bank sampah sampurna berkah

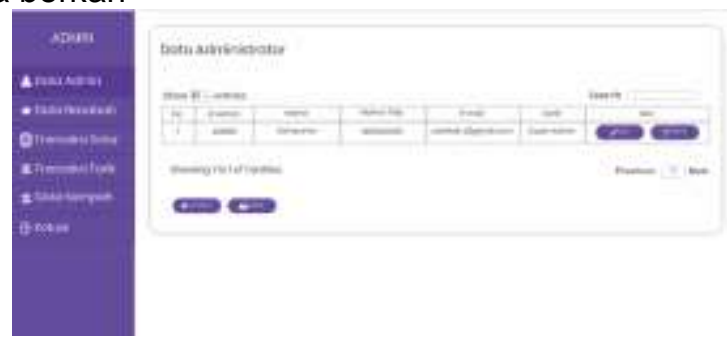

Gambar 6. Data Admin

c. Tampilan input dan data nasabah

Pada menu ini akan menampilkan data nasabah dari bank sampah, dimana data tersebut dapat diedit oleh admin, selain dapat mengedit data admin juga dapat menambahkan atau mendaftarkan nasabah baru dari bank sampah sampurna berkah. Pada sistem ini nasabah hanya bisa mendaftar melalui admin.
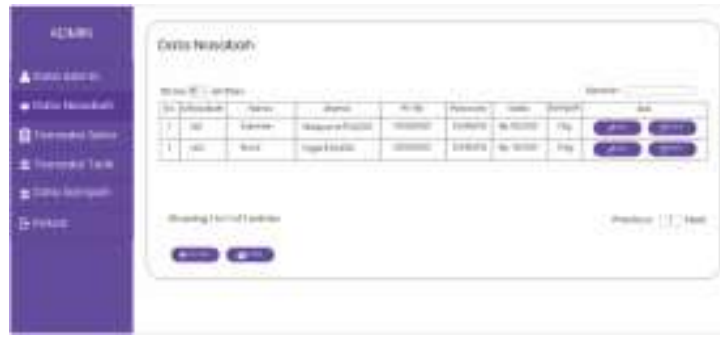

Gambar 7. Data Nasabah
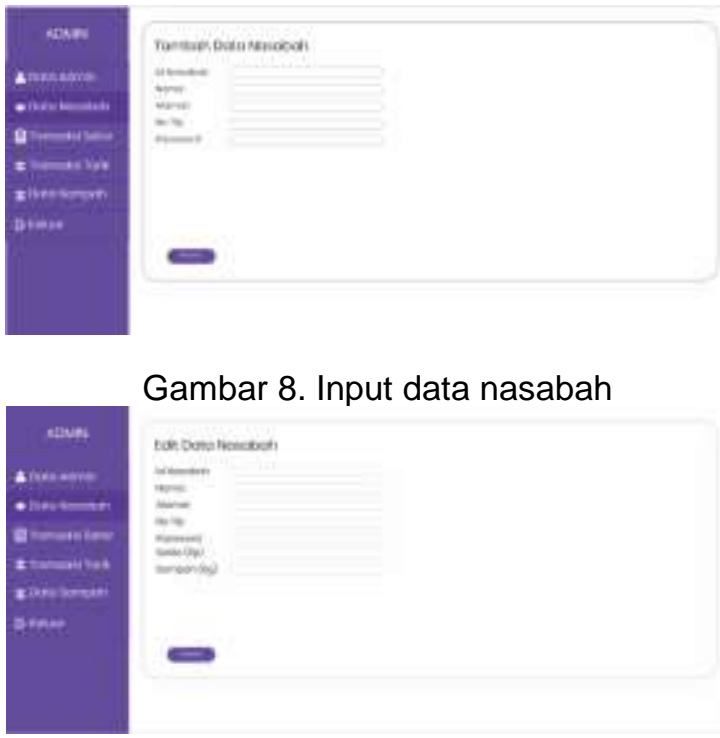

Gambar 8. Input data nasabah

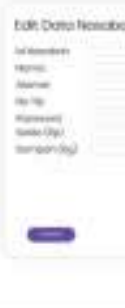

Gambar 9. Edit data nasabah 
d. Tampilan transaksi setor sampah

Proses transaksi setor sampah diinputkan oleh admin bank sampah. Pada menu ini admin memilih id nasabah, menginputkan berat sampah dan memilih id sampah yang nantinya secara otomatis akan keluar harga satuan dan total harga sampah, yang nantinya akan ditampilkan di data transaksi setoran.

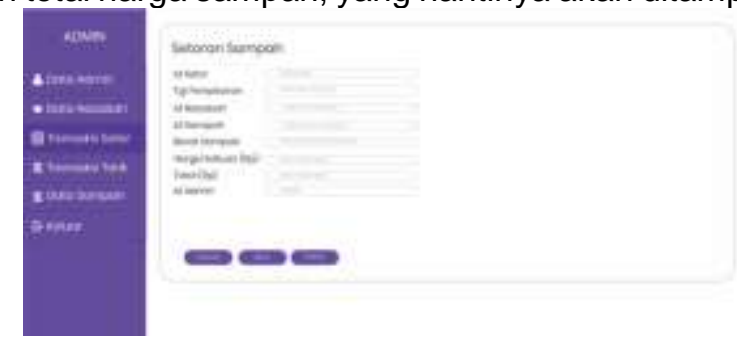

Gambar 10. Halaman Tambah Setor sampah

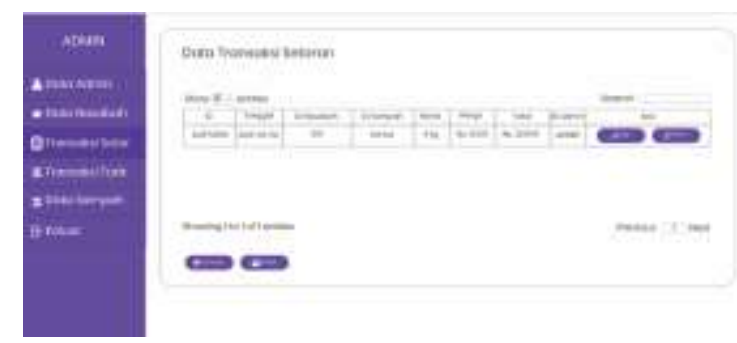

Gambar 11. Data Transaksi Setor sampah

e. Tampilan Transasaksi Tarik tabungan

Dalam proses penarikan tabungan oleh nasabah hanya dapat dilakukan melalui halaman admin, sehingga nasabah yang akan menarik hasil tabungannya harus lapora kepada admin bank sampah sehingga proses penarikan dapat diproses oleh admin.

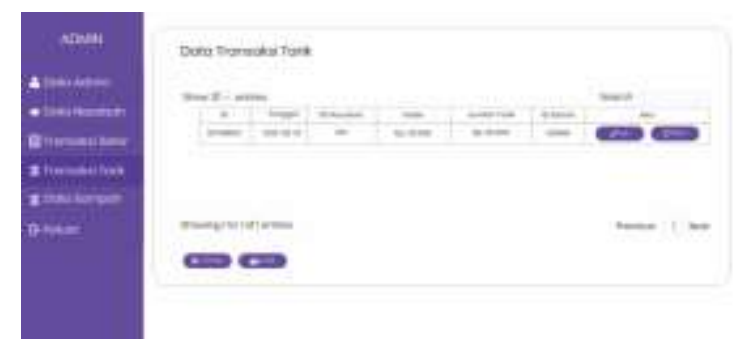

Gambar 12. Data Transaksi Tarik

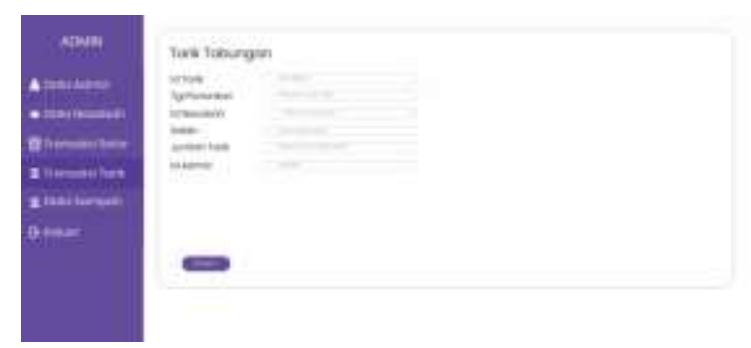

Gambar 13. Form Penarikan Tabungan

f. Tampilan tambah jenis sampah

Pada proses penambahan jenis sampah dilakukan oleh admin, penambahan dilakukan dengan mengisi id sampah, satuan sampah, harga serta deskripsi yang menjelaskan kategori sampah seperti apa yang termasuk dalam id sampah tersebut 


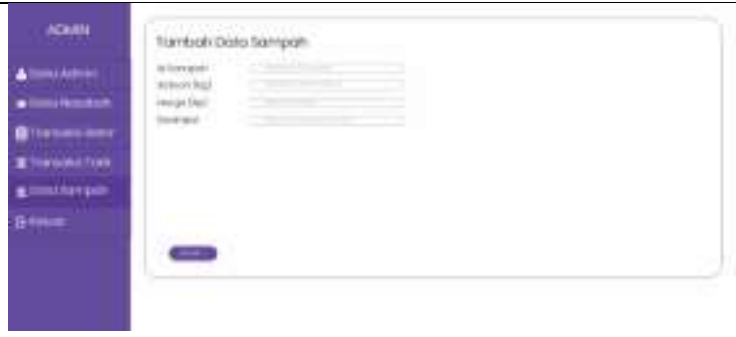

Gambar 14. Tambah Jenis Sampah

g. Tampilan pada sistem nasabah

Tampilan pada nasabah setelah melakukan login hanya dapat melihat data sampah, catatan setoran, catatan tarik tabungan yang tampil dalam bentuk tabel

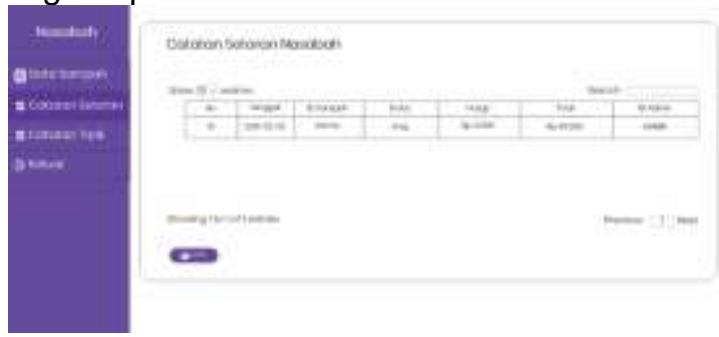

Gambar 14. Catatan Setoran Nasabah

\section{KESIMPULAN}

Dengan dibuatkannya aplikasi sistem informasi pengolahan bank sampah berbasis website ini diharapkan dapat membantu dan menjadi solusi bagi pengurus bank sampah "sampurna berkah" dalam mengelola dan memanaj transaksi dan laporan data nasabah dalam kegiatan tabung/setor sampah, dan juga akan meningkatkan pelayanan pengurus bank sampah terhadapa nasabah sehingga proses pelayanan bank sampah yang dulu membutuhkan waktu cukup lama menjadi lebih singkat dan pendek sehingga menghemat dari segi waktu yangdibutuhkan maupun cost/biaya yang dikeluarkan.

\section{REFERENSI}

Imaniawan, F. F. D., \& Elsa, U. M. (2017). Sistem Informasi Penjualan Sepatu Berbasis Web Pada Vegas Hyper Purwokerto. Ijse.Bsi.Ac.Id IJSE-Indonesian Journal on Software Engineering, 3(2). https://ejournal.bsi.ac.id/ejurnal/index.php/ijse/article/view/3000

Irnawati, O., \& Listianto, G. B. A. (2018). Metode Rapid Application Development (RAD) pada Perancangan Website Inventory PT. SARANA ABADI MAKMUR BERSAMA (S.A.M.B) JAKARTA . EVOLUSI: $\begin{array}{llll}\text { Jurnal Sains Dan } & \text { Manajemen, }\end{array}$ https://ejournal.bsi.ac.id/ejurnal/index.php/evolusi/article/view/4414

Komputer, W. (2014). Mudah Membuat Aplikasi SMS Gateway dengan Codelgniter - Wahana Komputer Google Buku. PT PT Komputindo. https://books.google.co.id/books?hl=id\&lr=\&id=Ut1MDwAAQBAJ\&oi=fnd\&pg=PP1\&dq=codeigniter+ adalah\&ots=fMkPG0c0jY\&sig=7T9VD5K8HfkKpRI0_FY44MWqWJI\&redir_esc $=\mathrm{y} \# \mathrm{v}=$ onepage $\& \mathrm{q}=\mathrm{co}$ deigniter adalah\&f=false

Latukolan, M. L. A., Arwan, A., \& Ananta, M. T. (2019). Pengembangan Sistem Pemetaan Otomatis Entity Relationship Diagram Ke Dalam Database. Jurnal Pengembangan Teknologi Informasi Dan IImu Komputer, 3, 4058-4065. http://j-ptiik.ub.ac.id/index.php/j-ptiik/article/view/5117

Maryani, I., Ishaq, A., \& Slamet Mulyadi, D. (2018). Sistem Informasi Pemesanan Minuman Berbasis Client Server Pada Kampung Dahar Purwokerto. EVOLUSI: Jurnal Sains Dan Manajemen, 6(2). https://ejournal.bsi.ac.id/ejurnal/index.php/evolusi/article/view/4455

Riyanto, A. D., \& Kusumastuti, G. (2015). PEMBANGUNAN SISTEM INFORMASI PENGOLAHAN DATA PADA TABUNGAN BANK SAMPAH "CERIA" PURWOKERTO. Telematika, 8(2), 1-17. http://ejournal.amikompurwokerto.ac.id/index.php/telematika/article/view/392

Sanubari, T., Prianto, C., \& Riza, N. (2020). Odol (one desa one product unggulan online) penerapan http://ejournal.bsi.ac.id/ejurnal/index.php/ijse 
Indonesian Journal on Software Engineering (IJSE)

Vol. 7, No. 1, Juni 2021, hlm. 78-85

p-ISSN: 2461-0690

Akreditasi KEMENRISTEKDIKTI, No. 85/M/KPT/2020

e-ISSN: 2714-9935

metode Naive $\quad$ Bayes pa... - $\quad$ Google $\quad$ Books. Kreatif.

https://www.google.co.id/books/edition/Odol_one_desa_one_product_unggulan_onlin/s4j_DwAAQB AJ?hl=id\&gbpv=0

Suryati, T. (2009). Bijak dan Cerdas Mengolah Sampah. PT Agromedia Pustaka. https://www.google.co.id/books/edition/Bijak_dan_Cerdas_Mengolah_Sampah/rGkINzHaLPsC?hl=i $\mathrm{d} \& \mathrm{gbpv}=1 \& \mathrm{dq}=$ Mengolah+Sampah + Rumah + Tangga \&printsec=frontcover

Sutabri, T. (2012). Analisis Sistem Informasi (C. Putri (ed.)). CV ANDI OFFSET. https://books.google.co.id/books?hl=id\&|r=\&id=ro5eDwAAQBAJ\&oi=fnd\&pg=PA1\&dq=Sistem+infor masi+adalah\&ots=WDheYI5jOe\&sig=_tc9HbIAHOy7g2bTHPEHXtawd9k\&redir_esc=y\#v=onepage\& $\mathrm{q}=$ Sistem informasi adalah\& $\mathrm{f}=\mathrm{false}$

Sutikno, S. (2019). Pengembangan Sistem Informasi Bidang Administrasi Desa Soket Dajah Kecamatan Tragah Berbasis Web. Jurnal Ilmiah Pangabdhi, 5(1). https://doi.org/10.21107/pangabdhi.v5i1.5163 